of pupils the task of creating that wider general understanding of science, its method, its potentialities and its limitations, which to-day is essential no less for the advance of science itself than for the realization of these full potentialities for human welfare that the application of science offers us.

\section{A NEW ADRENAL STEROID}

$\mathrm{T}$ HERE has been a recently growing body of evidence that the isolated and characterized adrenal steroids do not themselves account for all the actions of crude adrenal cortex extract. Tait, Simpson and Grundy, working at the Middlesex Hospital Medical School, London, have devised a method for the assay of the influence of adrenal steroids on the sodium and potassium ion balance by estimation of the diminution in the ratio of sodium-24 to potassium-42 in the urine of adrenalectomized rats, over a two-hour interval after the administration of the radioisotopes. In this way they found that crude ox adrenal extract contains a substance which behaves chromatographically like cortisone but which has a much greater effect on the sodium and potassium ion balance ${ }^{\mathbf{x}}$ A substance with similar properties was found to be present also in the blood of the adrenal vein ${ }^{2}$. Subsequent studies by Simpson and Tait and their colleagues have shown that a new adrenal steroid is responsible for these effects, and the provisional name of "electrocortin" has been suggested for this steroid ${ }^{3}$.

The isolation of electrocortin has proved to be a difficult task, and Drs. Simpson and Tait have called into collaboration Prof. T. Reichstein, of Basle, and his colleagues, whose experience in the isolation of steroid substances is unrivalled. Dr. A. Wettstein and Dr. R. Neber, of Ciba, Ltd., Basle, also collaborated in this work, which has resulted in the preparation of pure electrocortin 4 . From one ton of cattle adrenal glands only $10-40 \mathrm{mgm}$. of electrocortin was isolated.

Electrocortin proves to be much the most active steroid so far available in maintaining an adrenalectomized $\mathrm{dog}$ in good health, being thirty times as active as 11-deoxycorticosterone acetate in this respect; 11-deoxycorticosterone was hitherto by far the most active isolated substance known in tests of this sort. In the sodium-potassium balance test devised by Tait, Simpson and Grundy, electrocortin is about one hundred times as active as 11-deoxycorticosterone.

Almost simultaneously, Mason and his colleagues at the Mayo Clinic, Rochester, Minnesota, have announced the isolation of a similar substance from ox adrenal extracts ; while R. E. Knauff, E. D. Nelson and W. J. Haines, at the Upjohn Laboratories, Kalamazoo, Mich., have obtained a similar substance from pig adrenal extract . $^{6}$

Evidence about the structure of the new steroid is as yet fragmentary. It appears to be $a_{1} C_{21}$ steroid with a $\Delta-4 \alpha-\beta$ unsaturated ketone grouping and an $\alpha$-ketol side-chain at $C_{17}$. There is, in addition, a hydroxyl group the position of which has not been determined, but which appears not to be $17 \alpha, 16 \alpha$ or $\beta$, nor 11 or $12 \beta$. According to Knauff et al., the new steroid has little or no activity in the glycogen-deposition or eosinophil-depletion tests for adrenal steroids. This observation would be in agreement with the absence of an $11 \beta$ hydroxyl group.

In electrocortin we may well have the active principle of the amorphous fraction of crude adrenal extracts, the existence of which has been assumed for some time. Although electrocortin is much more active than deoxycorticosterone quantitatively, it seems likely that its actions will be qualitatively similar to those of deoxycorticosterone and of the amorphous fraction, and so any entirely new type of action will probably not be shown by electrocortin. Nevertheless, the isolation of this new steroid, springing as it does from researches at the Middlesex Hospital Medical School, has provided the solution to a problem of many years standing, and has opened up a new and important approach to the physiology of adrenal secretions.

It is unfortunate that the British pharmaceutical industry is poorly developed with respect to steroid preparation and chemistry, despite the excellent academic work in this field which has been carried out here during the past twenty-five years. Had the possibility existed in Great Britain of assisting the development of Simpson and Tait's researches on a large scale in industrial laboratories, we might have avoided yet another example of the necessity of transferring abroad for large-scale development an important new discovery made by British investigators.

1 Tait, J. F., Simpson, S. A., and Grundy, H. M., Lancet, i, 122 (1952). ${ }^{2}$ Simpson, S. A., Tait, J. F., and Bush, I. E., Lancet, ii, 226 (1952). ' Endocrinology, 50, 150 (1952). Acta Endocrinol., 11, 199 (1952); Mem. Soc. Endocrin., No. 2, 9 (1953).

'Simpson, S. A., Tait, J. F., Wettstein, A., Neber, R., Euw, J. v., and Reichstein, T., Experientia, 9, 33 (1953).

${ }^{5}$ Mattox, V. R., Mason, H. L., Albert A., and Code, C. F., J. Amer. Chem. Soc., 75, 4869 (1953).

${ }^{6} J$. Amer. Chem. Soc., 75, 4868 (1953).

\section{DOMESDAY BOOK RECORDS FOR EASTERN ENGLAND}

The Domesday Geagraphy of Eastern England

By Prof. H. C. Darby. Pp. xiv +400 . (Cambridge: At the University Press, 1952.) 55s. net.

TTHE Domesday Book contains so many figures 1 concerning the size and value of land holdings, the extent of wood, meadow and pasture, and the existence of mills, fisheries and salt-pans for the greater part of England, that generations of historians have wished that this information could be incorporated in maps that would illustrate the physical appearance and something of the economic activity of England about the year 1100. What was lacking was time for the calculations and certainty as to the meaning of the terms in which Domesday quantities were expressed. Prof. H. C. Darby, as this volume of four hundred pages and the promise 